\title{
Single wall carbon nanotubes enter cells by endocytosis and not membrane penetration
}

\author{
Peter N Yaron ${ }^{1}$, Brian D Holt ${ }^{2}$, Philip A Short ${ }^{2}$, Mathias Lösche ${ }^{2,3,4}$, Mohammad F Islam ${ }^{5^{*}}$ and Kris Noel Dahl $1^{1,2^{*}}$
}

\begin{abstract}
Background: Carbon nanotubes are increasingly being tested for use in cellular applications. Determining the mode of entry is essential to control and regulate specific interactions with cells, to understand toxicological effects of nanotubes, and to develop nanotube-based cellular technologies. We investigated cellular uptake of Pluronic copolymer-stabilized, purified $\sim 145 \mathrm{~nm}$ long single wall carbon nanotubes (SWCNTs) through a series of complementary cellular, cell-mimetic, and in vitro model membrane experiments.

Results: SWCNTs localized within fluorescently labeled endosomes, and confocal Raman spectroscopy showed a dramatic reduction in SWCNT uptake into cells at $4^{\circ} \mathrm{C}$ compared with $37^{\circ} \mathrm{C}$. These data suggest energy-dependent endocytosis, as shown previously. We also examined the possibility for non-specific physical penetration of SWCNTs through the plasma membrane. Electrochemical impedance spectroscopy and Langmuir monolayer film balance measurements showed that Pluronic-stabilized SWCNTs associated with membranes but did not possess sufficient insertion energy to penetrate through the membrane. SWCNTs associated with vesicles made from plasma membranes but did not rupture the vesicles.
\end{abstract}

Conclusions: These measurements, combined, demonstrate that Pluronic-stabilized SWCNTs only enter cells via energy-dependent endocytosis, and association of SWCNTs to membrane likely increases uptake.

\section{Background}

Carbon nanotubes (CNTs) have recently been explored for potential uses in biology and medicine. Their small size, high surface area, inert chemical composition, and unique physical properties have made them extensively investigated for transport of DNA[1], nucleic acids[2], drugs[3], and a variety of other potential therapeutics[4]. Single wall CNTs (SWCNTs) with a 1-2 nm outer diameter have variable length and unique optical and electrical properties[5] desirable for biological applications [6]. Cytotoxicity of SWCNTs depends on SWCNT length, impurities, and dispersion quality (isolated vs. bundles)[7]. SWCNTs dispersed in a biocompatible Pluronic triblock copolymer reorganize sub-cellular structures without inducing cell death[8,9]. To better understand the toxicological effects posed by SWCNTs and to develop SWCNT-related cellular biotechnologies,

\footnotetext{
*Correspondence: mohammad@cmu.edu; krisdahl@cmu.edu

'Department of Chemical Engineering, Carnegie Mellon University,

Pittsburgh, PA, USA

${ }^{5}$ Department of Materials Science \& Engineering, Carnegie Mellon University, Pittsburgh, PA, USA

Full list of author information is available at the end of the article
}

unambiguous determination of the mechanism of uptake into the cell is essential.

Competing hypotheses exist regarding the mechanism by which SWCNTs enter cells: non-specific physical penetration of the cell membrane, endocytosis or both. Numerous studies have imaged CNTs inside cells and have shown that CNTs are endocytosed[10-14]. Theoretical and simulation studies on CNT uptake into cells provided contradictory results: some theoretical reports have suggested that CNTs may not be able to trigger endocytosis due to their small diameter and the kinetics of endosome formation[15,16]. Simulation studies have shown that CNTs have affinity for membranes[17], but suggest that CNTs have insufficient energy to pierce through both leaflets of a membrane. While endocytosis is the commonly suggested mechanism of cellular uptake, physical penetration has not been rigorously considered and may account for significant uptake. In particular, alteration or disruption of sub-cellular membranous structures or CNT affinity to membranes may also be responsible for altering cellular uptake and architecture. 
Here, we employed complementary methods including in vitro model membranes and cellular imaging to investigate mechanisms of cellular uptake of short (145 \pm 17 nm), Pluronic F-127 (PF-127) triblock copolymerdispersed SWCNTs in Millipore-filtered deionized water to discern whether cellular uptake occurs only via an active endocytosis process or passive physical penetration through the membrane. To minimize confounding effects due to SWCNT sample preparation, such as contamination from metal catalysts, undesirable carbon polymorphs, distribution of SWCNT lengths, and defects resulting from functionalization methods, we utilized highly purified, length-selected, dispersed, pristine SWCNTs that have been previously developed in our group $[9,18,19]$. We have determined uptake and localization of Pluronic copolymer-stabilized SWCNTs into cells through temperature dependent cell studies with confocal Raman spectroscopy and fluorescence lifetime imaging (FLIM). We also used electrochemical impedance spectroscopy (EIS) of sparsely-tethered bilayer lipid membranes (stBLMs) and Langmuir monolayers (LMs) of synthetic phospholipids to model the plasma membrane. We further verified our results by examining interactions between SWCNTs and giant plasma membrane vesicles (GPMVs). GPMVs are produced from cell membranes, are more complex than synthetic lipid systems, but circumvent biological complications of cells. stBLMs, LMs and GPMVs have been utilized previously as model systems with great success to determine spatial localization, binding affinities, dissociation constants, and insertion pressures necessary for membrane association and cellular incorporation of materials[20-22].

\section{Results}

\section{SWCNTs added to the extracellular media localize within} cells

We confocally imaged the Raman spectra inside HeLa cells to visualize the sub-cellular localization of PF-127 stabilized SWCNTs. The Raman intensity distribution, obtained from the G-band $\left(1590 \mathrm{~cm}^{-1}\right)$ [13,23], shows SWCNT concentration localized to the mid-plane of a fixed, hematoxylin-labeled cell (Figure 1). SWCNTs were preferentially located within cells versus the extracellular regions, and most SWCNTs were localized at the perinuclear region (Figure 1). Similar cellular localization of SWCNTs has been previously observed $[10,13,24]$.

\section{Lipid bilayer association of SWCNTs}

To determine if SWCNTs perforate bilayers, and by a similar mechanism might penetrate the plasma membrane of the cell, we examined SWCNT interactions with synthetic lipid bilayers. We monitored the electric responses of sparsely-tethered bilayer lipid membranes
(stBLMs) to SWCNT addition using electrochemical impedance spectroscopy (EIS; Additional Methods and Additional Figure 1A). It was recently shown that stBLMs prepared by rapid solvent exchange[25] form complete bilayers on solid substrates that are contiguous and virtually defect-free[25]. These stBLMs are decoupled from the substrates by a highly hydrated, nanometer-thin stratum to retain their in-plane fluidity and, therefore, constitute realistic models of lipid membranes[22]. Specifically, they form fluid, disordered membranes with a resistance in the $\mathrm{M} \Omega \mathrm{cm}^{2}$ regime[24] that permits the sensitive detection of changes in their electrical properties by membrane-targeting enzymes[26] or channel-forming toxins[27,28].

SWCNTs dispersed with PF-127 were added to stBLMs prepared from DOPC to determine changes in membrane capacitance and resistance. EI spectra of the stBLM were collected at 0 minutes, 20 minutes and 18 hours for different concentrations of PF-127-stabilized SWCNTs and PF-127 without SWCNTs. The spectra are displayed as Cole-Cole plots (Figure 2A), which exhibited a semicircular shape, consistent with the capacitive properties of a near-ideally insulating dielectric layer (Figure 2A). Spectra were fit (solid lines) to an equivalent circuit model (ECM) that is effective for modeling dielectric properties of highly insulating solidsupported phospholipid bilayers[29] (see Methods, Additional Methods, and Additional Figure 1B). To compare the effects of SWCNTs on the bilayers, we normalized the parameters obtained from the fits to those obtained for the stBLM prior to SWCNT addition.

The results (Figure 2B-D and Additional Information) showed that the stBLMs possess near-ideal capacitive behavior. The exponents of the constant phase element (CPE; see Methods and Additional Methods) were always near unity with $\alpha_{\text {stBLM }}>0.95$, (Figure 2B) allowing the stBLM CPE in the ECM to be approximated as a capacitance $\mathrm{CPE}_{\mathrm{stBLM}} \approx C_{\mathrm{stBLM}}$. Tracking $C_{\text {stBLM }}$ versus incubation time (Figure $2 \mathrm{C}$ ) or concentration (Additional Information) showed a slight increase, indicating a small change in local dielectric constant in the hydrophobic core or in bilayer thickness. The second CPE in the ECM (see Additional Figure 1B), $C P E_{\text {defect }}$, depends on electrical conductivity of the sub-membrane space. Increased electric resistance of the aqueous reservoir leads to a higher electric field penetration into this space and, consequently, a smaller $\mathrm{CPE}_{\text {defect }}$. Assuming that ion mobility remains the same in the sub-membrane space as in the bulk of the electrolyte, this defect density in the stBLM may be estimated from $R_{\text {defect }}$. Changes in $R_{\text {defect }}$ versus incubation time (Figure 2D) and concentration (Additional Information) were negligible, suggesting no change in bilayer defect density due to changes induced by incubation with SWCNTs. For 


\section{Raman}

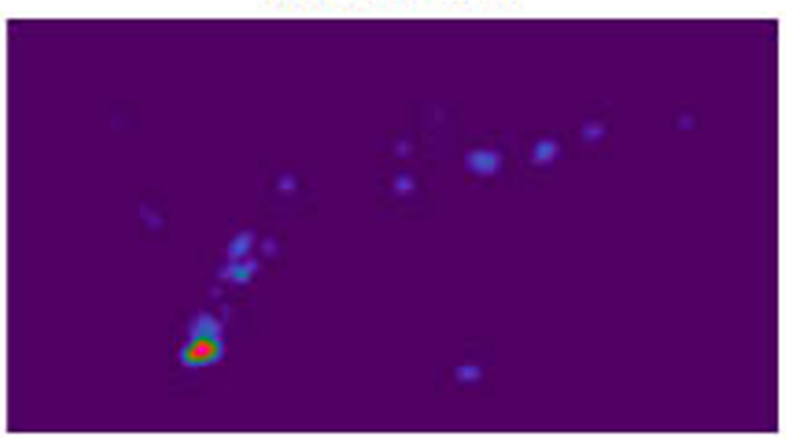

Min

Figure 1 SWCNTs localized within cells visualized by confocal Raman spectroscopy. A confocal Raman image (with $100 \times$ oil objective, data acquired in $1 \mu \mathrm{m}$ increments) was acquired of the focal plane of a fixed, hematoxylin-labeled HeLa cell that had been exposed to SWCNTs for 2 days. The left image shows the spatial distribution of the SWCNT (G-band) Raman intensity, and the right image superimposes the Raman intensity onto a phase contrast image. SWCNT intensity was sub-cellularly localized, preferentially in the perinuclear regions and the cytoplasm. This image is representative of more than 10 imaged cells.
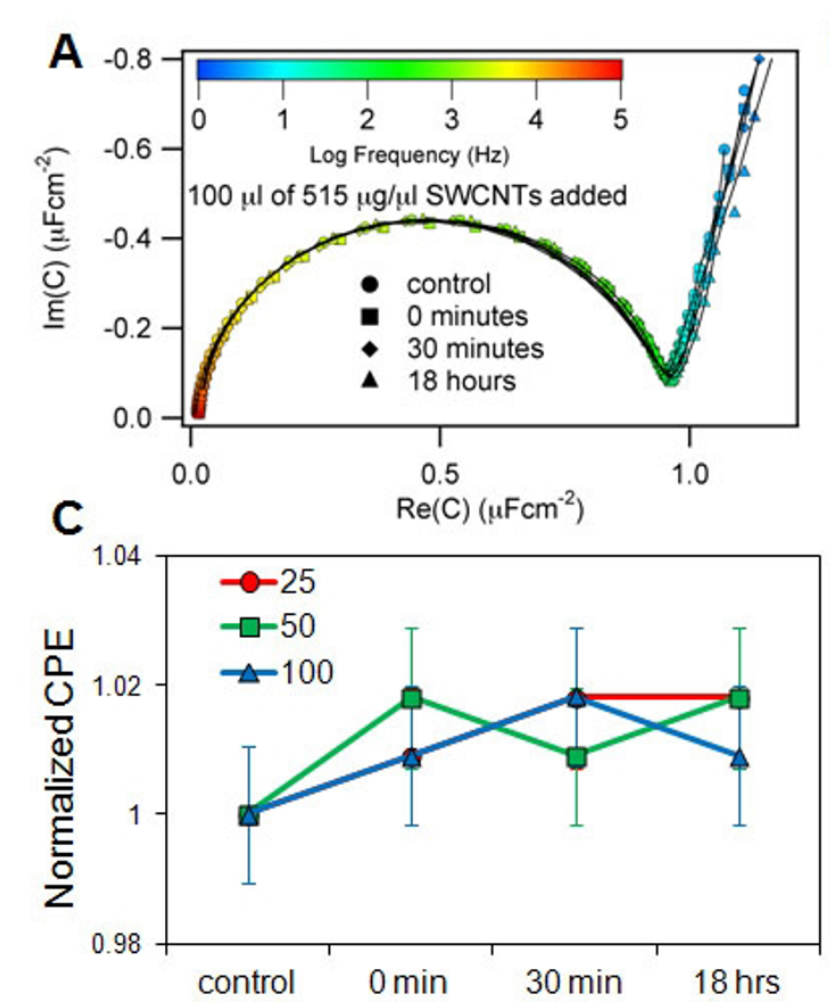

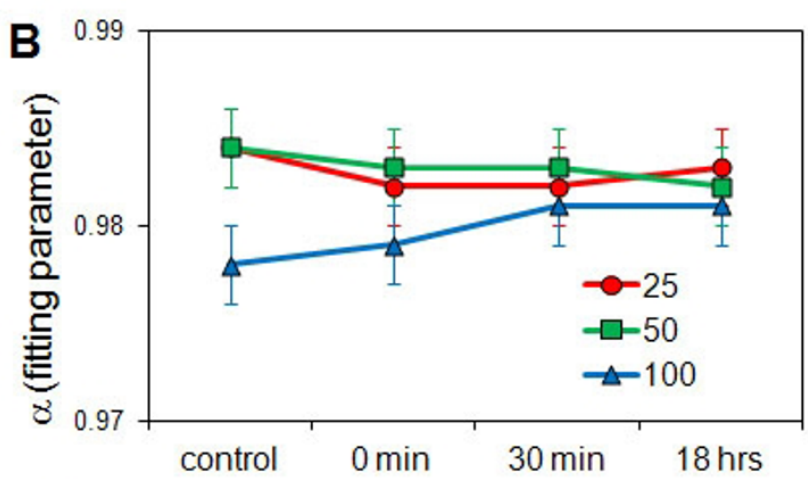

D

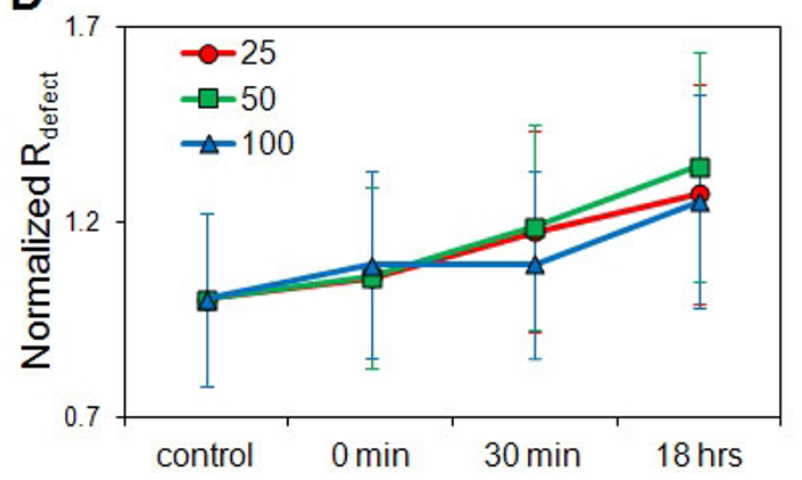

Figure 2 SWCNTs and PF-127 do not alter membrane capacitance of stBLM. (A) EIS data was analyzed as a Cole-Cole plot of the stBLM before and after exposure to SWCNTs dispersion. The imaginary versus the real $(\operatorname{Im}(C)$ vs. $\operatorname{Re}(C))$ parts of capacitance sweeps from $0.1 \mathrm{~Hz}$ to $60,000 \mathrm{~Hz}$ were plotted as an overlaid color spectrum. Exposure to SWCNTs showed little change to the stBLM indicating no penetration or intercalation into the membrane leaflets. (B) Model fit of the ECM showed little change in $\alpha(\alpha>0.95)$, suggesting a near perfect membrane. (C and $\mathbf{D})$ Model fit of the normalized CPE $E_{\text {stBLM }}$ and $R_{\text {defect }}$ values showed little change in membrane properties after treatment. As a comparison, disruption or perforation of membranes changes $R_{\text {defect }}$ by more than $100 \times$. 
comparison, $R_{\text {defect }}$ may change by more than two orders of magnitude when stBLMs are perforated by protein membrane pores or reduced in their thickness, leading to a lower hydrophobic barrier to ion transfer across the bilayer[27,28]. While the SWCNTs did not affect the capacitance or resistance of the membrane significantly, there were long-term changes in the membrane properties in the presence of PF-127 and SWCNTs suggesting some reordering of the membranes.

\section{Interaction of SWCNTs with Langmuir monolayers}

To test if SWCNTs partially incorporate into the membrane[17] we investigated the interaction of SWCNTs with Langmuir monolayers (LMs). LMs, although only one half of a lipid bilayer, allow quantification of the thermodynamics of the membrane interface with an aqueous environment[30-32]. Specifically, LMs allow control of the surface pressure, $\Pi$ and the interfacial energy, $\gamma$, via adjustments of the interfacial area, A, within the Langmuir trough. At low surface pressures, which correspond to high surface energy $\left(\Pi=\gamma_{0}-\gamma\right.$, where $\gamma_{0}$ is the energy of the bare aqueous surface), penetration of a material into the lipid film is strongly favored. Incubation of a pre-formed phospholipid LM at constant area $A_{0}$ therefore leads to an increase of the initial surface pressure from $\Pi_{i}=\Pi\left(\mathrm{A}_{0}\right)$ to $\Pi_{\mathrm{i}}+\Delta \Pi$ due to incorporation of the adsorbent. The observed value of $\Delta \Pi$ depends on the interaction of the adsorbent with the membrane interface and is reduced if the initial value of $\Pi$ is increased in a series of experiments. For protein adsorbents, the reduction in $\Delta \Pi$ is approximately linear in response to increases in $\Pi\left(\mathrm{A}_{0}\right)$ and can be extrapolated to $\Delta \Pi=0$ to determine the maximum insertion pressure (MIP), $\Pi^{*}$, i.e. the initial surface pressure at which no more adsorbent can penetrate the LM [20]. It is commonly assumed that an adsorbent will likely insert into bilayer membranes of the same composition as the LM if $\Pi^{*}>30-35 \mathrm{mN} / \mathrm{m}$ because this is the approximate value at which a LM is in a thermodynamic state equivalent to that of the respective bilayer membrane[31,33,34]. MIP experiments were carried out with SWCNTs stabilized with PF-127 polymer and with the PF-127 polymer alone using DPPC in a LM (Figure 3). Extrapolation of $\Delta \Pi$ vs. $\Pi_{i}$ yielded MIP values just below the bilayer-equivalent pressure, $28-30 \mathrm{mN} / \mathrm{m}$ (Table 1). This is consistent with previous reports that Pluronics (poloxamers) are able insert into membranes and alter membrane fluidity and membrane defects[35].

At room temperature, DPPC forms phase-separated LMs in a coexistence regime, which complicates the determination of the SWCNTs' MIP[20]. To confirm MIP results in a purely fluid lipid phase, similar experiments were performed using DOPC LMs. However, due

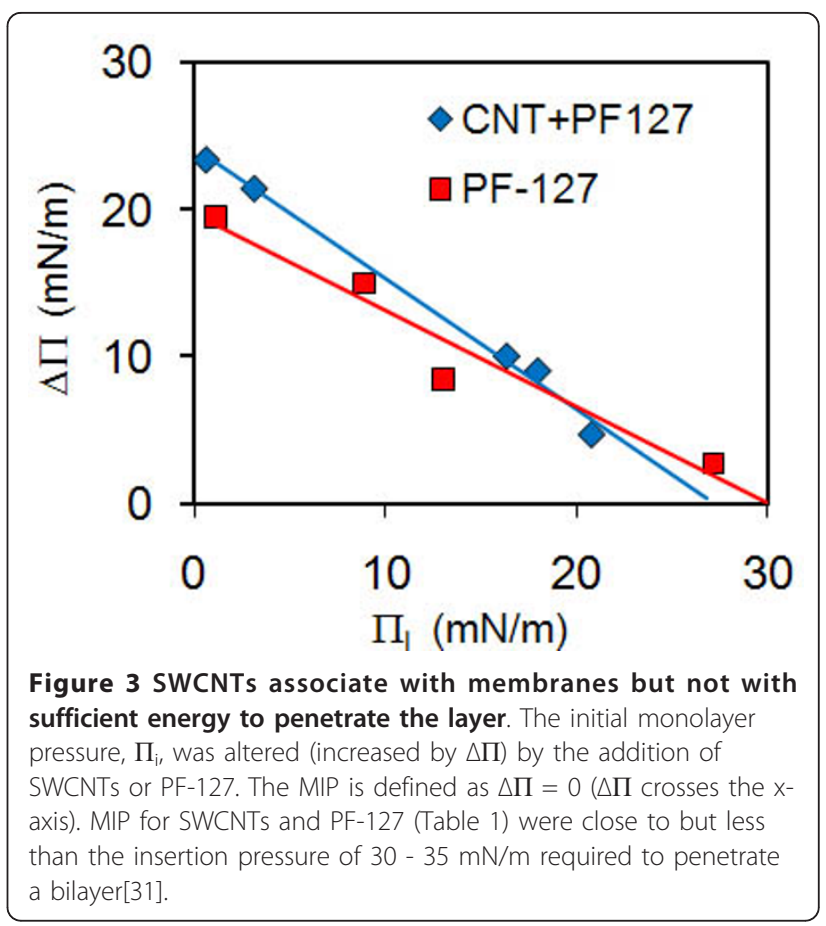

to its higher fluidity than DPPC, DOPC LMs are intrinsically less stable, making reproducibility an issue[32]. We never observed any pressure increase $\Delta \Pi$ at initial pressures exceeding $22 \mathrm{mN} / \mathrm{m}$, but we were unable to produce a MIP plot of similar accuracy to that obtained using DPPC.

PF-127 has a higher MIP than the PF-127 stabilized SWCNTs (Table 1), suggesting that the free polymer has a higher affinity for the membrane. To determine if the PF-127 dispersant was separating from the SWCNTs and formed aggregates in the experiments, we took samples from the subphase of the Langmuir film balance after experiments and checked for SWCNT aggregates using Vis-NIR absorbance spectroscopy. There was no significant change observed compared with a freshly-dispersed nanotube solution.

\section{FLIM of CellMask orange-labeled GPMVs with SWCNTs}

To determine if SWCNTs have a preferential association with bilayer membranes and to provide a link between synthetic lipid and cell experiments, we visualized SWCNT interactions with vesicles derived from cell

Table 1 MIP calculated from linear fits of DPPC monolayers exposed to SWCNTs dispersed in PF-127 and to PF-127 alone

\begin{tabular}{lll}
\hline & MIP $(\mathbf{m N} / \mathbf{m})$ & $\mathbf{R}^{\mathbf{2}}$ \\
\hline PF-127 & 30.0 & 0.946 \\
SWCNT & 28.9 & 0.993 \\
\hline
\end{tabular}


plasma membranes. GPMVs, produced from NIH-3T3 cells (see Methods), were labeled with CellMask orange and exposed to SWCNTs at similar time points and concentration as the other experiments. GPMVs were imaged via widefield microscopy for $>2$ hours, and no vesicle rupture was observed.

We performed fluorescence lifetime imaging microscopy (FLIM) of the CellMask orange with the SWCNTs. When fluorophores are excited with a femtosecond excitation pulse, the emission photons are detected after excitation and the distribution can be modeled as a single- or multi-exponential decay curve with characteristic time constant(s), $\tau$. FLIM is sensitive to the local $(\sim 5 \mathrm{~nm})$ nanoenvironment including proximity to quenching molecules but is independent of fluorophore concentration, photobleaching and excitation light intensity [36]. CellMask orange was best modeled with a double exponential decay, as judged from the observation of improved fits to a double exponential decay without over-parameterization ( $\chi^{2}$ closest to unity) and dissimilar time constants with non-statistical amplitudes[36]. SWCNT-treated samples showed a statistically significant reduction in mean fluorescence lifetime, $\tau_{\mathrm{m}}$, compared to control (Figure 4A, B and Table 2). For $\tau_{1}, \tau_{2}$ and $\tau_{\mathrm{m}}$, the SWCNT-treated samples possessed a shorter lifetime ( $p$ $<0.01$ for $\tau_{1}$ and $\tau_{\mathrm{m}}$ ), suggesting that SWCNTs were sufficiently close to the membrane label to quench the fluorescence lifetime of the CellMask orange.

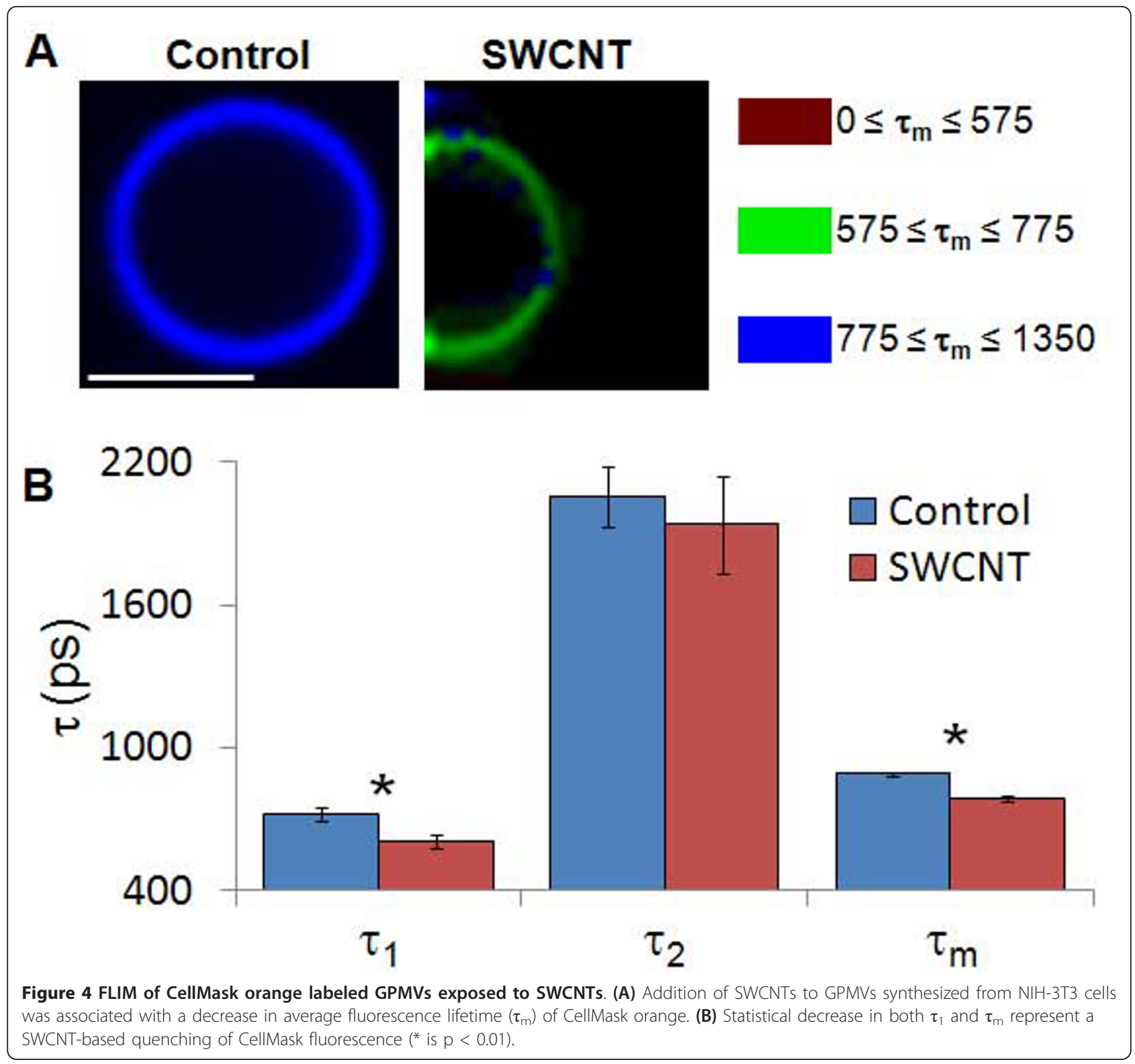


Table 2 Fluorescence lifetime imaging microscopy (FLIM) values obtained from CellMask Orange-treated GPMVs exposed to SWCNTs

\begin{tabular}{lllllll}
\hline \multicolumn{2}{l}{ FLIM of GPMVs with CellMask Orange (+) SWCNTs } & & & \\
& $\boldsymbol{\tau}_{\mathbf{1}}$ & $\mathbf{A}_{\mathbf{1}}$ & $\boldsymbol{\tau}_{\mathbf{2}}$ & $\mathbf{A}_{\mathbf{2}}$ & $\boldsymbol{\tau}_{\mathbf{m}}$ & $\boldsymbol{\chi}^{\mathbf{2}}$ \\
\hline Control & $721 \pm 90$ & $0.829 \pm 0.186$ & $2055 \pm 464$ & $0.171 \pm 0.066$ & $890 \pm 32$ & $1.357 \pm 0.089$ \\
$\mathbf{3 0}$ min. & $505 \pm 62$ & $0.859 \pm 0.099$ & $1861 \pm 462$ & $0.141 \pm 0.032$ & $674 \pm 20$ & $1.462 \pm 0.073$ \\
\hline
\end{tabular}

\section{Temperature-dependent endocytosis assay}

We have shown with in vitro assays that SWCNTs do not penetrate either synthetic or plasma membrane derived bilayers. To perform the analogous experiments in cells, we obtained confocal Raman spectra of HeLa cells that were maintained at either $37^{\circ} \mathrm{C}$ or $4^{\circ} \mathrm{C}$ (Figure $5 \mathrm{~A}$ ). At $4^{\circ} \mathrm{C}$, active cellular processes including endocytosis are inhibited. These cells were not labeled with hematoxylin so sub-cellular features are not clearly visible in phase-contrast images. SWCNTs interacted with the cells at both $37^{\circ} \mathrm{C}$ and $4^{\circ} \mathrm{C}$ after only 45 minutes of incubation, but the SWCNT G-band Raman intensity was stronger for the $37^{\circ} \mathrm{C}$, sample (Figure 5A). Zooming into regions of SWCNT intensity (boxes) revealed that cellular localization of SWCNTs was different for the $37^{\circ} \mathrm{C}$ and $4^{\circ} \mathrm{C}$ samples (Figure 5B). At $37^{\circ} \mathrm{C}$ SWCNTs were primarily contained within the cell (dashed to enhance cellular borders). The $4^{\circ} \mathrm{C}$ sample showed SWCNT intensity preferentially located outside of and at the edge of the cell with only a small fraction interacting with the cell (Figure 5B).

To quantify SWCNT distribution in the cells at $37^{\circ} \mathrm{C}$ and $4^{\circ} \mathrm{C}$, we collected confocal Raman spectra in the $\mathrm{x}-\mathrm{y}$ plane and then scanned along $\mathrm{z}$-direction (height of the cell) from -20 to $20 \mu \mathrm{m}$ with a $1 \mu \mathrm{m}$ z-step size. We arbitrarily designated $\mathrm{z}=0$ to be $\sim 2 \mu \mathrm{m}$ from the basal plane. We independently determined the cell height to be $\sim 7 \mu \mathrm{m}(\mathrm{z}=-2 \mu \mathrm{m}$ to $\mathrm{z}=5 \mu \mathrm{m})$ using the laser scanning confocal microscope. SWCNTs for the $37^{\circ} \mathrm{C}$ sample were located in a $\mathrm{z}$ region approximately corresponding to the height of the cell (Figure 5C). Conversely, the $4{ }^{\circ} \mathrm{C}$ sample did not show SWCNT intensity for height regions corresponding to the cell height (Figure 5C). Minimal SWCNT intensity was observed below $\mathrm{z}=-2 \mu \mathrm{m}$, corresponding to the SWCNTs on the substrate, and above $\mathrm{z}=5 \mu \mathrm{m}$, corresponding to SWCNTs on the cell membrane.

\section{Altered endocytosis rates in SWCNT treated cells}

We showed that the uptake of PF-127 stabilized SWCNTs was energy-dependent, but we also performed more direct measurements of endocytosis. Endocytosis in HeLa cells was visualized using a GFP-tagged RhoBGTPase (pAcGFP-1-endo, Clontech, further referred to as GFP-endo), which labels endosomes in mammalian cells. Cells fixed at set time points after SWCNT treatment were imaged for endosomes (Figure 6A) and quantified using Image (Figure 6B). While uncertainties in this measurement exist from exogenous expression of the marker, widefield imaging, and image analysis capturing potentially errant signal (see Methods), the control sample showed remarkable precision from cell to cell and experiment to experiment (Figure 6A, control and $0 \mathrm{~min}$ ). We saw slight increases in endosome numbers per cell with increased time of exposure to SWCNTs, with a statistically significant increase in endosome number at 20 and 25 minutes. Thus, treatment with SWCNTs appeared to alter cellular endocytosis after 20 minutes.

\section{FLIM of endosomes}

Using FLIM, we directly visualized SWCNT interaction with fluorescent endosomes. For all treatment conditions, the fluorescence lifetime of GFP and GFP-endo was best modeled as a double exponential decay (Tables 2 and 3). GFP and GFP-endo showed a majority $\tau_{\mathrm{m}}$ of 2-3 ns (Figure 7), which is consistent with previously reported FLIM of GFP in HeLa cells[37]. We treated cells expressing GFP (soluble in the cytoplasm) or GFPendo with SWCNTs added at a final concentration of $100 \mu \mathrm{g} / \mathrm{mL}$ at $\mathrm{t}=0$ and followed the mean fluorescence lifetime, $\tau_{\mathrm{m}}$, at 5 minutes and 25 minutes - before and after the observed changes in endosomes per cell shown in Figure 6. We saw a decrease in the $\tau_{\mathrm{m}}$ of GFP-endo after 5 minutes of treatment with SWCNTs (Figure 7A, 5 minutes, green spots at the periphery) and more significantly after 25 minutes (Figure 7A, 25 minutes, red and green spots). FLIM of GFP (in the cytoplasm) averaged over the cell showed a similar decrease in fluorescence lifetime at short time (Figure 7B, $5 \mathrm{~min}$ ). To determine whether SWCNT length affected cellular uptake, we treated HeLa cells with long SWCNTs (1250 $\mathrm{nm}$ versus $145 \mathrm{~nm}$ ) and found that the $\tau_{\mathrm{m}}$ for GFP-endo fluorescence was unchanged after the addition of long SWCNTs (Figure 7C).

Quantification of $\tau_{\mathrm{m}}$ from the different experimental conditions (Figure 7A-C) showed time-dependent changes (Figure 7D). Treatment with short SWCNTs generated a statistically significant $(\mathrm{p}<0.01)$ reduction in $\tau_{\mathrm{m}}$ after 5 minutes for both GFP-endo and GFP compared to their respective controls. At 25 minutes after treatment, the GFP $\tau_{\mathrm{m}}$ remained significantly reduced. 


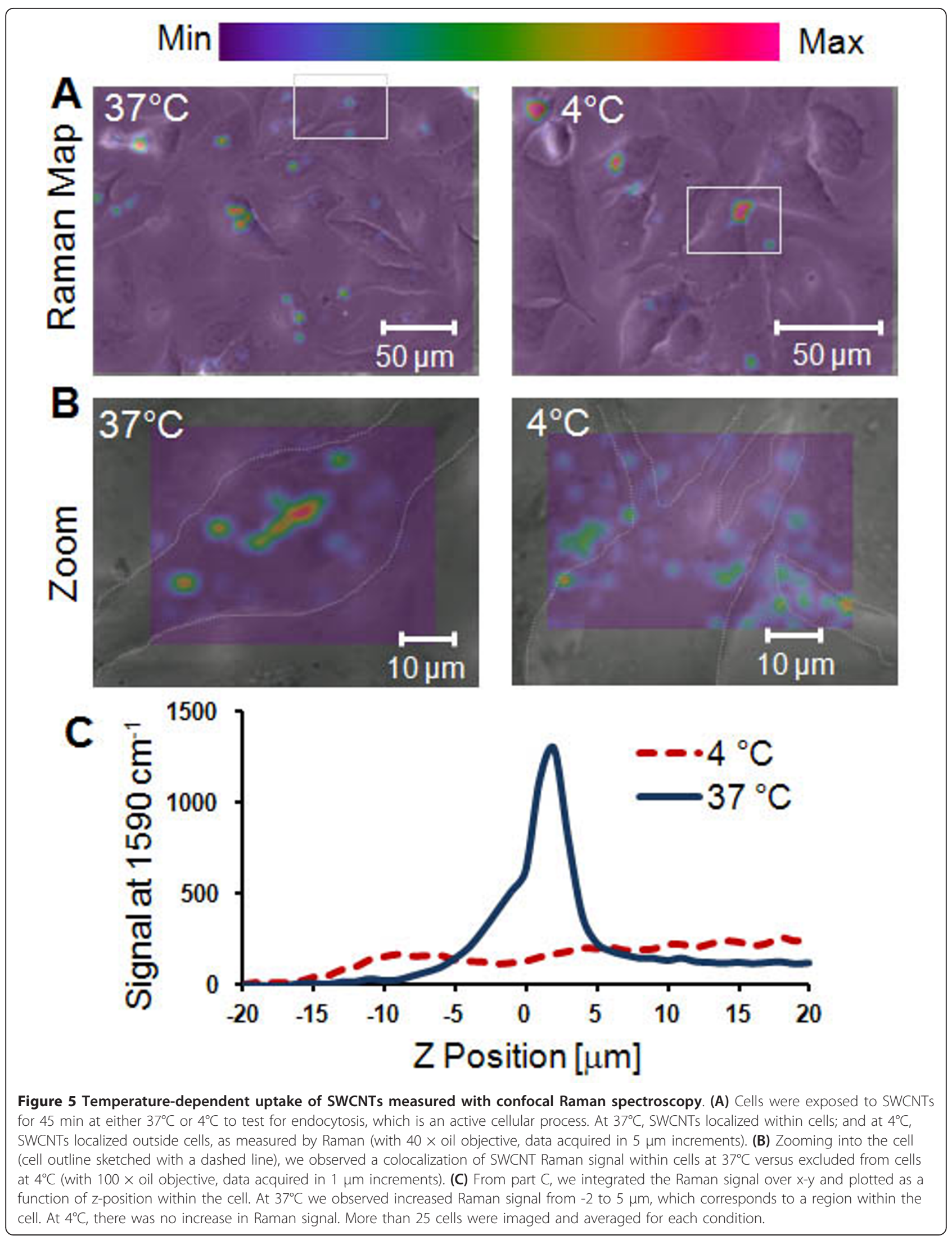



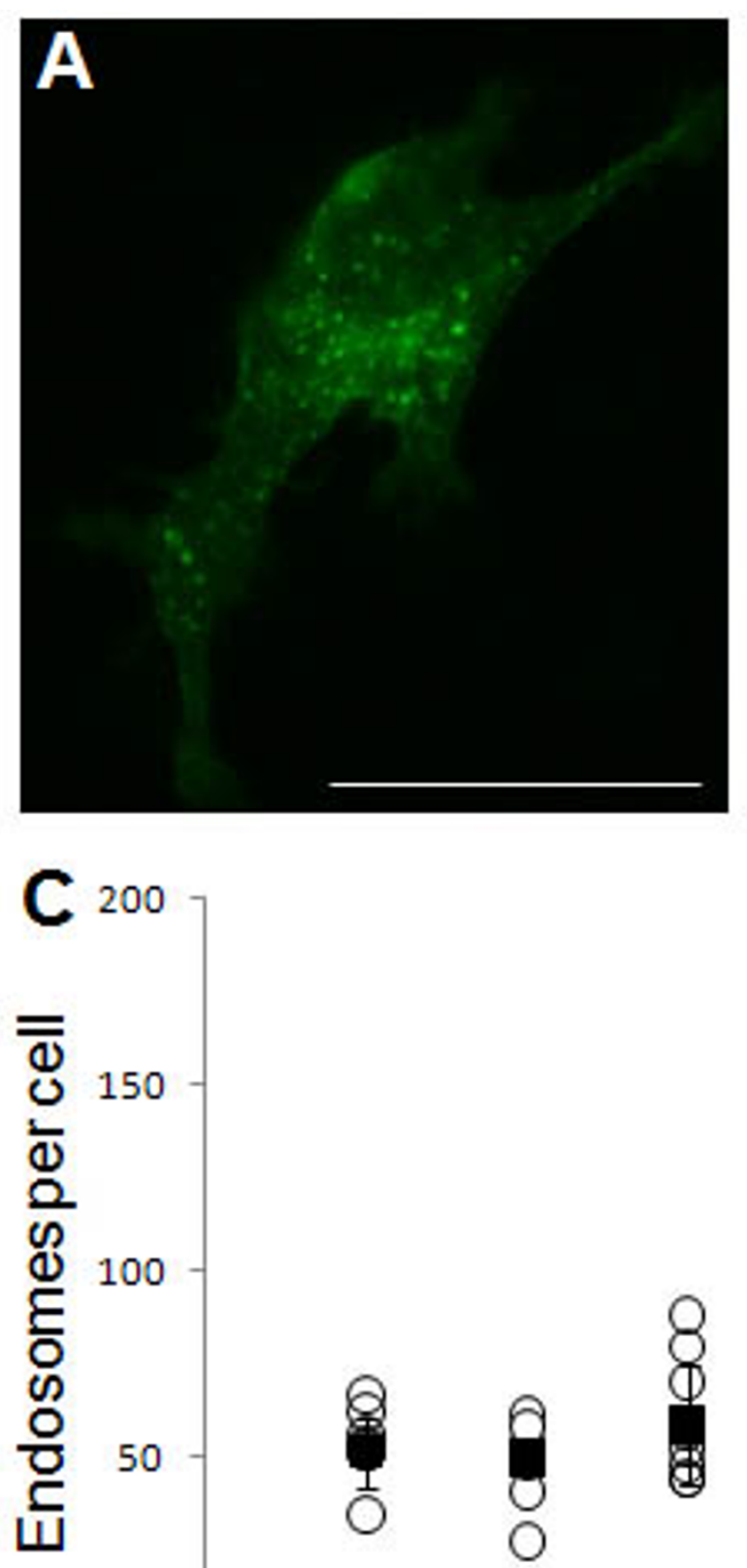
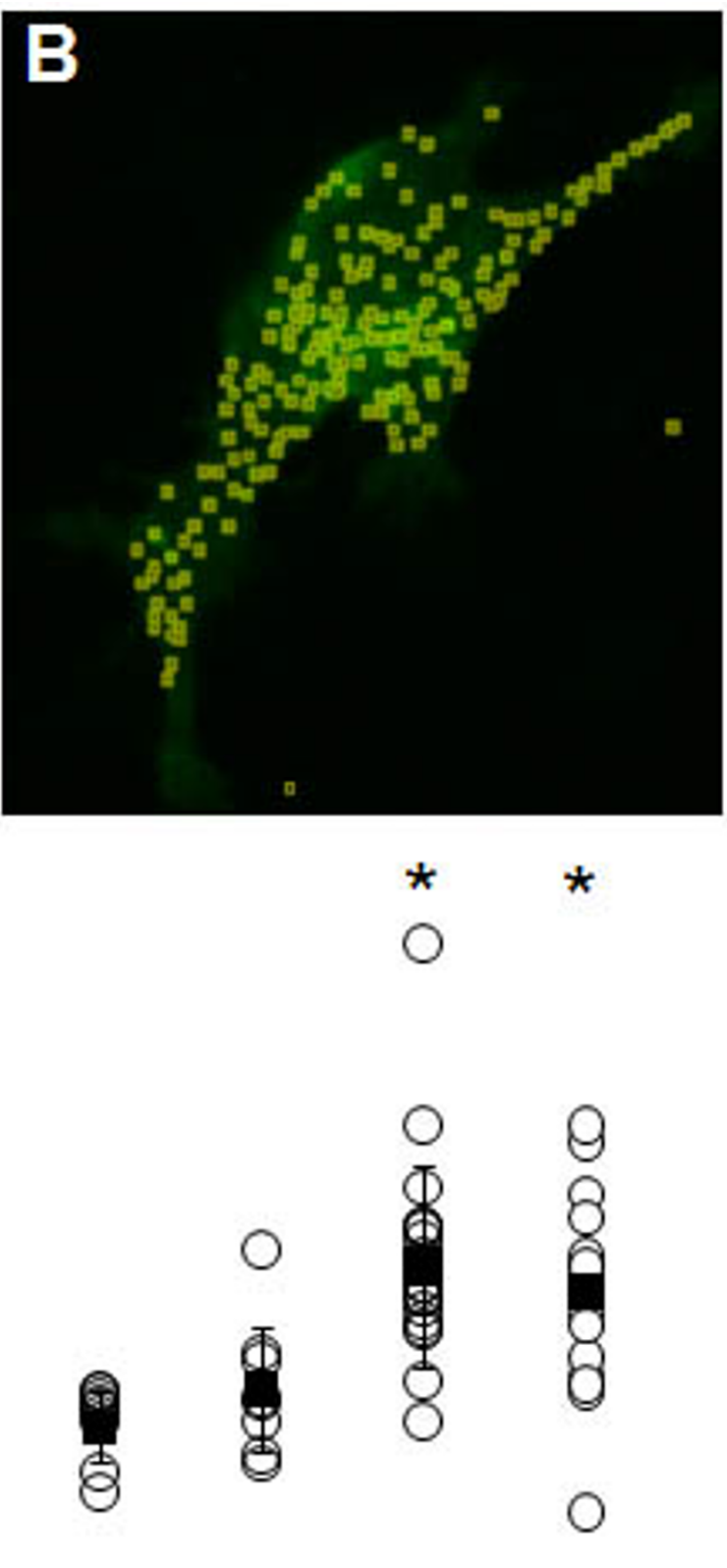

0

\section{ctrl}
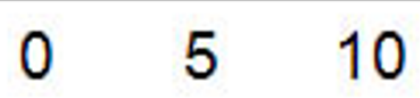

15

20

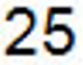

\section{Time after treatment $(\mathrm{min})$}

Figure 6 Treatment with SWCNTs increases the endosomes per cell. (A) Cells were transfected with GFP-endo (Rho-GTPase), a marker for endocytosis, and treated with $100 \mathrm{\mu g} / \mathrm{mL}$ SWCNTs. Cells were then fixed at set timepoints after treatment and rapidly imaged by widefield microscopy. (B) The observable endosomes were segmented and counted using ImageJ. Errant points, such as those outside the cell, were identified and removed from the counts. The number of endosomes was determined by an average of $n=30$ cells per treatment over 2 treatments at all time points. (C) After treatment with SWCNTs there was an apparent increase in endosomes per cell. After 20 min, this change became statistically significant from control $(p<0.001)$. Open circles are individual cells and black boxes are the average with an SEM error bar. 
However, the GFP-endo $\tau_{\mathrm{m}}$ increased at 25 minutes. This suggests that HeLa cells had begun increasing the number of endosomes after 25 minutes (such as in Figure 6) which returned some of the signal to a more-baseline level. Also SWCNTs may have escaped from the endosomes, so they would no longer quench GFP-endo, but rather soluble GFP in the cytoplasm. The long SWCNTs showed no change in $\tau_{\mathrm{m}}$ at 5 minutes of treatment and only a slightly decrease in $\tau_{\mathrm{m}}$ at 25 minutes suggesting incubation with long SWCNTs does not alter the GFP fluorescence lifetime. Raw FLIM data is available in Table 3: $A_{1}$ and $A_{2}$ are the average relative contributions of $\tau_{1}$ and $\tau_{2}$ to $\tau_{\mathrm{m}}$ (Eq. 1 in Methods); average $\tau_{\mathrm{m}}$ cannot be calculated directly from averaging $\mathrm{A}_{\mathrm{i}}$ and $\tau_{\mathrm{i}}$.

\section{Discussion}

Previous studies involving several different cell types have demonstrated uptake of various types of functionalized CNTs[38-43]. Most studies show that CNTs enter cells via endocytosis[10-14]. However, given that millions of CNTs can enter cells[44], a small fraction of CNTs piercing the membrane could be significant. Some theoretical analyses suggested that SWCNTs may be insufficient to trigger endocytosis due to their small diameter and the kinetics of endosome formation[15,16]. Experiments using nanoparticles of varying size and composition determined that uptake of nanoparticles depends strongly on their size[11,15,45]. However, given the unique anisotropy of SWCNTs, it is unclear which orientation governs interactions with cells[16,46]. Using complementary membrane and cellular techniques we have shown unambiguously that polymer-dispersed SWCNTs were unable to penetrate complete bilayers. However, the affinity of the SWCNTs for membranes did appear to increase rates of endocytosis in the cell.

\section{Endocytosis of SWCNTs}

Confocal Raman spectroscopy and imaging of HeLa cells revealed that SWCNTs were preferentially localized within the cell. SWCNTs were observed throughout the cell with SWCNT intensity located in the perinuclear region, consistent with previous observations[10,24], possibly suggesting that SWCNTs entered cells via endocytosis and were deposited in or near the endoplasmic reticulum. This is also supported by a reduction in cellular uptake of SWCNTs at $4^{\circ} \mathrm{C}$ when energy-dependent processes, including endocytosis, are reduced. We suggest that SWCNTs or PF-127 by means of their membrane activity were able to disrupt some of the endosomes as they shrank into lysosomes, thus depositing SWCNTs throughout the cell and enabling them to interact with other cellular components[9].

SWCNTs enter cells via an energy-dependent endocytosic process. However, endocytosis may proceed by a number of different mechanisms including clathrinmediated endocytosis, calveoli-mediated endocytosis and pinocytosis (see review of nanomaterial uptake by endocytosis [45]). In this study we have not examined the specific type of endocytosis relevant for SWCNT uptake which could be further clarified by targeting integrins and other cell-specific receptors on the plasma membrane.

SWCNTs associate with but do not penetrate membranes Synthetic membrane experiments indicated that SWCNTs cannot completely penetrate membrane bilayers, but changes in monolayer pressure suggested that SWCNTs might penetrate the outer leaflet of lipids. We hypothesize that the association of SWCNT with lipids may alter membrane tension locally and stimulate endocytosis $[47,48]$. Exposure of cells to SWCNTs

Table 3 Fluorescence lifetime imaging microscopy (FLIM) values obtained from cells transfected with GFP-endo and GFP and exposed to SWCNTs

\begin{tabular}{|c|c|c|c|c|c|c|}
\hline \multicolumn{7}{|c|}{ GFP-endo (+) "Short" (145 \pm 17 nm) SWCNTs } \\
\hline & $\tau_{1}$ & $A_{1}$ & $\tau_{2}$ & $\mathrm{~A}_{2}$ & $\tau_{\mathrm{m}}$ & $\chi^{2}$ \\
\hline Control & $1732 \pm 65$ & $0.574 \pm 0.081$ & $2784 \pm 76$ & $0.426 \pm 0.074$ & $2128 \pm 37$ & $1.200 \pm 0.037$ \\
\hline $5 \mathrm{~min}$. & $1588 \pm 117$ & $0.601 \pm 0.105$ & $2757 \pm 116$ & $0.399 \pm 0.068$ & $1982 \pm 56$ & $1.291 \pm 0.088$ \\
\hline $25 \mathrm{~min}$. & $1918 \pm 124$ & $0.553 \pm 0.109$ & $2560 \pm 101$ & $0.447 \pm 0.104$ & $2176 \pm 58$ & $1.346 \pm 0.072$ \\
\hline \multicolumn{7}{|c|}{ GFP (+) "Short" (145 $\pm 17 \mathrm{~nm})$ SWCNTs } \\
\hline & $\tau_{1}$ & $A_{1}$ & $\tau_{2}$ & $\mathrm{~A}_{2}$ & $\tau_{\mathrm{m}}$ & $\chi^{2}$ \\
\hline Control & $1638 \pm 83$ & $0.558 \pm 0.133$ & $2803 \pm 107$ & $0.442 \pm 0.125$ & $2098 \pm 75$ & $1.261 \pm 0.082$ \\
\hline $5 \mathrm{~min}$. & $1306 \pm 146$ & $0.624 \pm 0.173$ & $3054 \pm 136$ & $0.376 \pm 0.132$ & $1959 \pm 98$ & $1.364 \pm 0.206$ \\
\hline $25 \mathrm{~min}$. & $1574 \pm 186$ & $0.568 \pm 0.163$ & $2527 \pm 118$ & $0.432 \pm 0.138$ & $1947 \pm 86$ & $1.342 \pm 0.099$ \\
\hline \multicolumn{7}{|c|}{ GFP-endo (+) “Long” (1.25 $\pm 0.75 \mu \mathrm{m})$ SWCNTs } \\
\hline & $\tau_{1}$ & $A_{1}$ & $\tau_{2}$ & $A_{2}$ & $\tau_{\mathrm{m}}$ & $\chi^{2}$ \\
\hline Control & $1945 \pm 131$ & $0.550 \pm 0.111$ & $2606 \pm 107$ & $0.450 \pm 0.109$ & $2230 \pm 60$ & $1.231 \pm 0.063$ \\
\hline $5 \mathrm{~min}$. & $2026 \pm 167$ & $0.534 \pm 0.110$ & $2515 \pm 121$ & $0.466 \pm 0.101$ & $2227 \pm 70$ & $1.456 \pm 0.101$ \\
\hline $25 \mathrm{~min}$. & $1827 \pm 151$ & $0.583 \pm 0.097$ & $2639 \pm 111$ & $0.417 \pm 0.088$ & $2137 \pm 59$ & $1.337 \pm 0.064$ \\
\hline
\end{tabular}




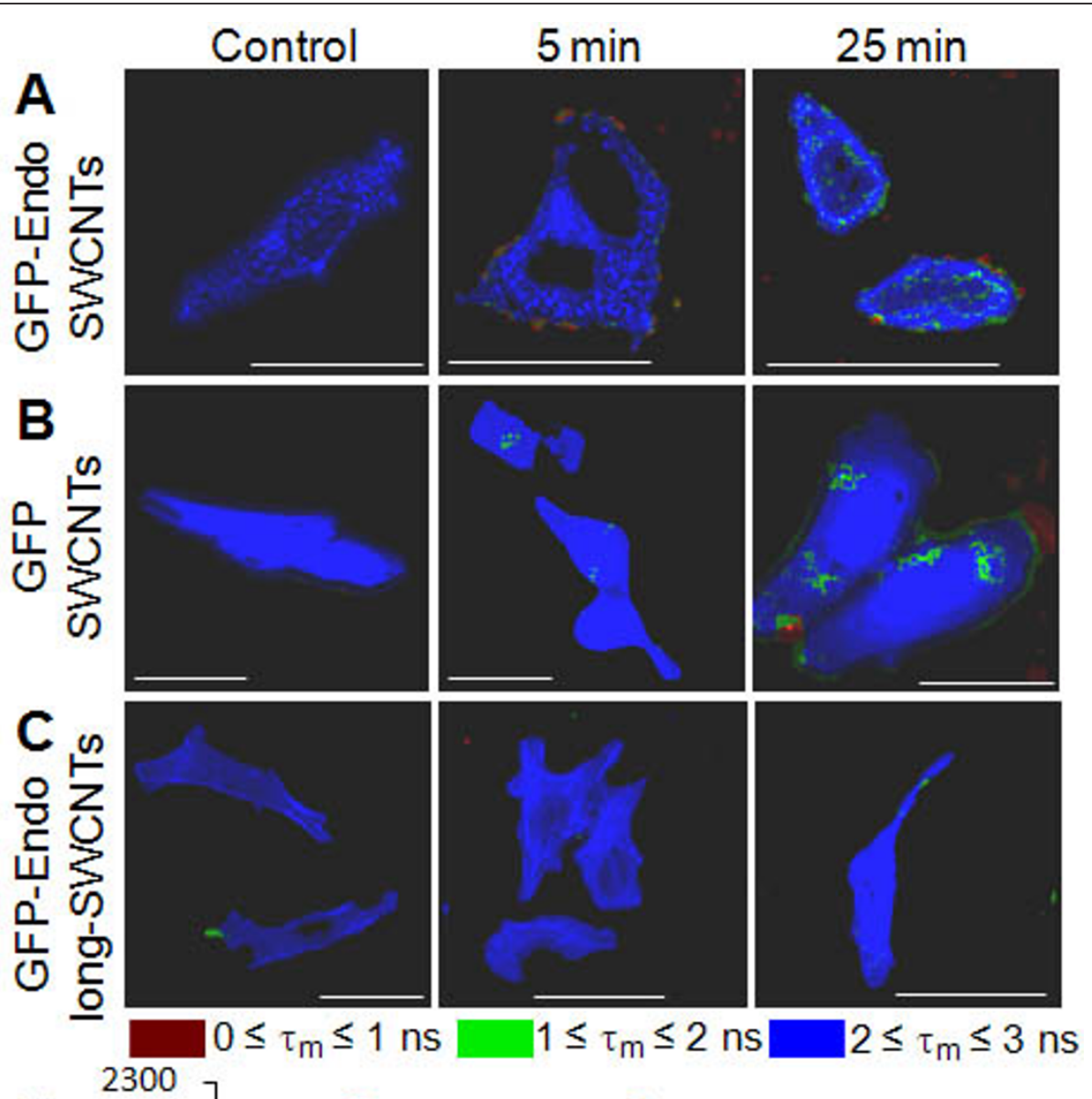

D 2300

$\tau_{\mathrm{m}}(\mathrm{ps})$

2050

1800

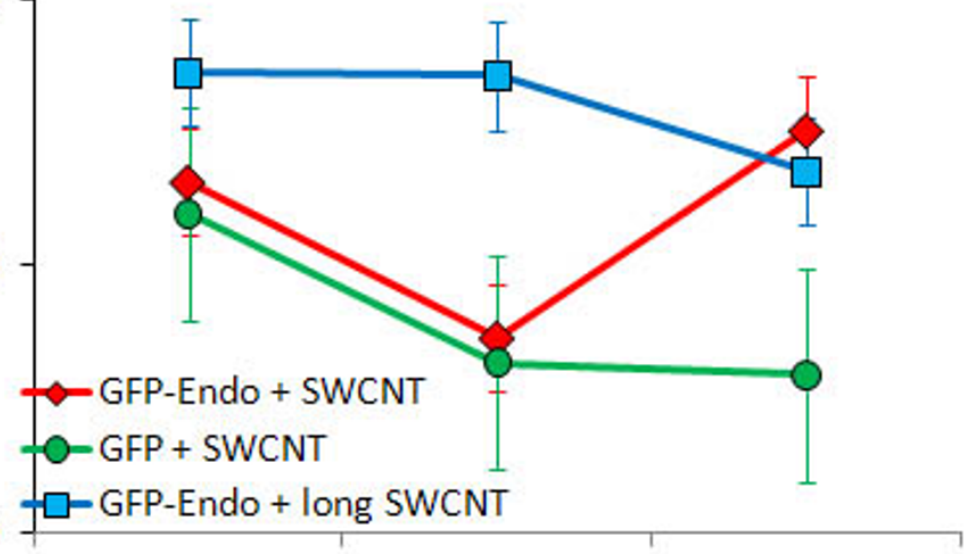

\section{${ }^{0}{ }^{5}$ Time after treatment $(\min )^{25}$}

Figure 7 FLIM of cytoplasmic GFP and GFP-tagged endosomes in cells exposed to SWCNTs. (A) Addition of SWCNTs was associated with a decrease in GFP mean fluorescence lifetime ( $\tau_{\mathrm{m}}$, pseudo-colored red to green to blue). This change in $\tau_{\mathrm{m}}$ was most obvious at the periphery of the cell and moved inward over longer times, as seen by more internal green regions and a more severe quenching (green to red) at the periphery. (B) Expression of soluble GFP in the cytoplasm also showed a reduction in $\tau_{\mathrm{m}}$ upon incubation with SWCNTs. (C) Treatment of cells with long SWCNTs (1250 nm vs. $145 \mathrm{~nm}$ ) showed little change in the GFP-endo $\tau_{\mathrm{m}}$. (D) Quantification of the $\tau_{\mathrm{m}}$ revealed time-dependent behavior. The $\tau_{m}$ of GFP-endo is significantly $(p<0.01)$ reduced after 5 min of SWCNT exposure but recovered to near control levels after 25 min of exposure. Similarly, the $\tau_{m}$ of cytoplasmic GFP significantly $(p<0.01)$ decreased after 5 min of SWCNT treatment; however, unlike GFPendo, it remained quenched after 25 min of exposure to SWCNTs. The $\tau_{\mathrm{m}}$ of GFP-endo, when exposed to long SWCNTs was relatively unchanged. 
significantly increased the number of endosomes when compared to control (Figure 4). Therefore, we suggest that SWCNTs affect the tension of the cell membrane, which may lead to a significant increase in endocytotic activity.

We have shown that short (145 nm) SWCNTs altered the fluorescence lifetime of GFP-endo, which label endosomes. While it is possible that these SWCNTs only indirectly alter the fluorophore's nanoenvironment, we have also shown that long $(1,250$ $\mathrm{nm}$ ) SWCNTs had no effect on lifetime compared to control, and these long SWCNTs are too long for endocytosis $[11,15,45]$. Further, confocal Raman imaging confirmed that short SWCNTs entered HeLa cells, probably via endocytosis as evidenced by the perinuclear localization. We propose that short SWCNTs in endosomes directly altered the $\tau_{\mathrm{m}}$ of the GFP-endo fluorophore; long SWCNTs, unable to enter via endocytosis, did not alter the $\tau_{\mathrm{m}}$ of GFP-endo. Soluble GFP was quenched 5 and 25 min after treatment, suggesting that SWCNTs were liberated from endosomes and quenched non-localized cellular GFP, further confirming the SWCNT sub-cellular localization, independently demonstrated via confocal Raman imaging. Unlike the GFP-endo, the GFP remained quenched after $25 \mathrm{~min}$, suggesting that some endosomes may have ruptured and released SWCNTs into the intracellular space and that the rate of entry of SWCNTs into the cell is decreased at long time.

\section{Potential mechanisms of SWCNT uptake}

In combination, the wide range of techniques used in this work shows conclusively that short Pluronic-coated SWCNTs enter the cell via endocytosis and not via membrane penetration. From our results we suggest that the mechanism of SWCNT uptake into cells includes the following steps: (A) SWCNTs adsorb onto the cell surface and penetrate into the outer leaflet of the bilayer. (B) This association increases membrane tension and induces an imbalance between the outer leaflet and the inner leaflet. (C) Localized disturbances in membrane tension can stimulate endocytosis as the membrane attempts to regulate tension. (D) Once endocytosis is stimulated, the SWCNTs localize in the endosomes, which shrink during processing. (E) By disruption of the endosomes or lack of lysosomal processing, SWCNTs enter the cytoplasm.

The fate of the Pluronic polymer outside or inside the cell remains unknown. Polymer-coated SWCNTs have been shown to adsorb protein when injected into the circulation of animals[49]. We did not observe the Pluronic being displaced by protein in solution over 6 days with agitation (Additional Figure 2). However, the complex mixture of different proteins, surfactants and cellular secretions in the circulation and in cell culture media may prove to displace Pluronic from the SWCNTs. As such we cannot assess at what point PF127 is lost from the tubes.

The pluronic coating likely increases the association of the SWCNTs with membranes, enhancing endocytosis. Since surfactant molecules are generally used to disperse SWCNTs in solutions, we believe that our results are generic features of SWCNT uptake into cells. The specific targeting of SWCNTs for use in therapeutics should also focus on endocytosis as the preferential method for the cellular uptake.

\section{Conclusions}

We have shown that short, polymer-dispersed SWCNTs enter the cells by endocytosis, and SWCNTs do not penetrate through bilayers non-specifically. There is a preferential interaction of SWCNTs with membranes, which likely increases rates of endocytosis after $\sim 30$ minutes. Thus the membrane affinity of SWCNTs control cellular uptake, but incorporation does not occur by passive membrane penetration.

\section{Methods}

\section{Synthesis of SWCNTs}

Details of the synthesis and dispersion of SWCNTs[9,19] are described in detail in the Additional Methods.

\section{Cell Culture and Imaging}

HeLa cells were grown in Dulbecco's Modified Eagle Medium (DMEM; Hyclone catalog number SH30021) with $10 \%$ fetal bovine serum (FBS) and 1\% penicillin/ streptomycin (both Invitrogen), collectively referred to as cell culture media (CCM). Cells were passaged onto \#1.5 coverslips in $35 \mathrm{~mm}$ dishes, incubated for $12-24$ hours and exposed to SWCNTs in $2 \mathrm{~mL}$ of CCM. Solutions were equally distributed over the cells, and CCM was pre-heated for most experiments. For $4^{\circ} \mathrm{C}$ cell culture experiments, the CCM was removed and the cells washed with phosphate buffer saline (PBS) at room temperature before $2 \mathrm{~mL}$ of $4^{\circ} \mathrm{C} C C M$ with SWCNTs was added, and the plate was immediately transferred to a $4^{\circ}$ $\mathrm{C}$ cold-room for $15 \mathrm{~min}$.

Cells were transferred to coverslips in $35 \mathrm{~mm}$ dishes or 6-well plates and were treated with $1 \mathrm{~mL}$ of SWCNTs diluted in CCM; SWCNT concentrations and times are reported in the results section for particular experiments. For imaging, cells on coverslips were washed twice with PBS at room temperature, fixed for 10 min with $3.7 \%$ formaldehyde (Sigma-Aldrich) and mounted onto slides. For some Raman imaging experiments, hematoxylin (Sigma-Aldrich) was added before mounting to enhance contrast of cellular features, but most cells were not labeled. 
Brightfield and widefield fluorescence imaging of the cells was performed with $40 \times$ (oil, 1.25 N.A.) or $63 \times$ (oil, 1.4 N.A.) objectives on a Leica DMI6000 B inverted microscope. Confocal Raman spectroscopy was performed on an inverted Raman confocal microscope (inVia, Renishaw) with a $785 \mathrm{~nm}$ laser (100 $\mathrm{mW}$ ) using either a $40 \times($ oil, 1.25 N.A.) or $100 \times$ (oil, 1.4 N.A.) objective (Leica Microsystems). The in-plane $(x-y)$ resolution of the Raman microscope with the $100 \times$ objective is $\sim 250 \mathrm{~nm}$ and the $\mathrm{z}$ resolution is $\sim 300 \mathrm{~nm}$. Confocal Raman spectra between 1327 and $1819 \mathrm{~cm}^{-1}$ were collected with a $0.82 \mathrm{~cm}^{-1}$ resolution. We then quantified the Raman intensity at $1590 \pm 17$ $\mathrm{cm}^{-1}$ to obtain intensity maps of SWCNTs; the tangential mode of graphene, called the G-band, is located at $1590 \mathrm{~cm}^{-1}$ and is widely used to identify SWCNTs[13,23]. Image analysis was performed using WiRE (Renishaw), and z-section data were analyzed using MATLAB (MathWorks) code developed in the lab.

\section{Cell Transfection and Imaging of Endosomes}

For transient transfection, cells were grown to $~ 60 \%$ confluence and transfected with either pAc-GFP1-Endo or pEGFP-C1 (Clontech) using PolyFect (Qiagen) according to manufacturer's recommendations, and cells were incubated overnight. To measure changes in endocytosis, cells were incubated with $100 \mu \mathrm{g}$ of SWCNTs in CCM for 0 (added and immediately washed), 5, 10, 15, 20 and $25 \mathrm{~min}$ at $37^{\circ} \mathrm{C}$ in the tissue culture incubator. At the selected time points, the CCM with SWCNTs was removed, and cells were washed, fixed and mounted as described above. All procedures were performed in low light to prevent GFP photobleaching during incubation, fixation, mounting, and transportation.

Confocal imaging caused photobleaching of small spots and could not be used to image endosomes in the entire cell, so we used widefield fluorescence imaging. To minimize artifacts of out-of-plane light, cells were imaged in the central plane, as identified by the z-position at which the nucleus was in best focus. Previous analysis has shown that there was no change in overall height in SWCNT-treated cells[9]. Images were processed with ImageJ to identify GFP-labeled endosomes by their fluorescence intensity and minimum and maximum sizes.

\section{Giant Plasma Membrane Vesicles (GPMVs)}

Vesicles were produced from NIH-3T3 cells grown in DMEM (Hyclone SH30022) supplemented with 10\% calf serum and $1 \%$ penicillin/streptomycin in $60 \mathrm{~mm}$ dishes at $80-90 \%$ confluence using a method described elsewhere[50,51]. Briefly, each dish was washed twice with $10 \mathrm{~mL}$ of a freshly prepared and thoroughly mixed buffer containing $10 \mathrm{mM}$ HEPES, $0.15 \mathrm{M} \mathrm{NaCl}, 2 \mathrm{mM}$ $\mathrm{CaCl}_{2}$, and $0.05 \% \mathrm{v} / \mathrm{v}$ gelatin. Cells were then incubated in $5 \mathrm{~mL}$ of buffer plus $1 \mathrm{mM}$ dithiotheritol (DTT) and $25 \mathrm{mM}$ formaldehyde for 1 hour at $37^{\circ} \mathrm{C}$ on an orbital shaker at $75 \mathrm{rpm}$. The solution was gently decanted and allowed to sit for $15 \mathrm{~min}$ at $4^{\circ} \mathrm{C}$ in a conical tube. Samples were taken from the middle portion of the solution to minimize extracellular material and necrotic cells. GPMVs were imaged directly using widefield microscopy or were treated with the membrane-active CellMask orange fluorophore (Invitrogen) with gentle agitation for $5 \mathrm{~min}$. Then, $0.5 \mathrm{~mL}$ of the GPMV solution was transferred to a $35 \mathrm{~mm}$ glass-bottom dish (MatTek) pre-incubated with poly-L-lysine solution (SigmaAldrich).

\section{Fluorescence Lifetime Imaging (FLIM)}

FLIM was performed using a Leica TCS SP5 inverted laser scanning confocal microscope with a $100 \times$ (oil, 1.4 N.A.) objective with a pixel resolution of $256 \times 256$ and a scan rate of $400 \mathrm{~Hz}$. A tunable $(720-950 \mathrm{~nm})$, mode-locked Ti:sapphire pulsed infrared laser (Chameleon, Coherent) served as the multiphoton (MP) excitation source (1 W, average). Pulse-widths of $<140 \mathrm{fs}$ were delivered at $90 \mathrm{MHz}$. For GFP, the MP laser was tuned to $942 \mathrm{~nm}$, and the FLIM-dedicated photomultiplier tube (PMT) was tuned to 481-615 nm to detect the full range of GFP emission. For CellMask orange, the MP laser was tuned to $900 \mathrm{~nm}$ with the PMT tuned to $550-700 \mathrm{~nm}$.

Time-correlated single photon counting (TCSPC) was implemented using a Becker \& Hickl SPC-830 acquisition package with $10 \mathrm{ps}$ resolution that includes three software programs: DCC (controls DCC 100 hardware), SPCM (controls image acquisition), and SPCImage (controls lifetime data analysis). Lifetime images were acquired for $180 \mathrm{~s}$ to minimize the coefficient of variation to $\sim 2.5 \%[52,53] .220$ time channels and a measurement window of $10.8 \mathrm{~ns}$ were used to minimize the variance of lifetime over a wide range of ratios of the measurement window to lifetime[53]. The rates of the detected, converted, and stored photons were maintained between $1 \times 10^{4}$ and $1 \times 10^{6}$ ( $<1 \%$ of laser repetition rate) to prevent errors in lifetime determination due to the pileup effect[53], to achieve the required signal-to-noise ratio after $3 \mathrm{~min}$ of detection, and to minimize photobleaching.

\section{FLIM Data Processing}

Fluorescence lifetime analysis was performed using SPCImage (Becker \& Hickl). Instrument response functions were estimated and manually verified through the SPCImage software for each data set[53]. Lifetime images were binned to achieve a peak photon count of 
$\geq 1000$ ( $\geq 50,000$ photons over all time channels), ensuring that two exponential decays could be accurately resolved[53,54].

Fluorescence lifetime is modeled as a sum of exponential decays, taking the form:

$$
I(t)=I_{0}+\sum_{n} a_{n} \exp \left(\frac{-t}{\tau_{n}}\right)
$$

where $I(t)$ is the number of photons detected per time, $I_{0}$ is a background offset, $a_{n}$ is the normalized amplitude, and $\tau_{\mathrm{n}}$ is the lifetime of the $\mathrm{n}^{\text {th }}$ exponential decay. For multi-exponential decays, a mean lifetime, $\tau_{\mathrm{m}}$, is defined as

$$
\tau_{m}=\frac{\sum_{n} a_{n} \tau_{n}}{\sum_{n} a_{n}}
$$

Each pixel was separately modeled as a single and a double exponential decay, and the corresponding average lifetimes $\left(\tau_{1}, \tau_{2}\right.$ and $\left.\tau_{m}\right)$, goodness of fits $\left(\chi^{2}\right)$, and standard deviations were calculated in MATLAB. Reported lifetime values (Tables 2 and 3) were averaged and errors were calculated using the derivative method of error propagation. Thus, the spatially average values presented in Table 3 will comply with Eq. 2 for the individual values. Fluorescence lifetime images were then generated using SPCImage.

\section{Sparsely-Tethered Bilayer Lipid Membranes (stBLMs)}

The synthetic, zwitterionic phospholipids used in the model membrane experiments, i.e., dipalmitoyl-sn-glycro-3-phosphocholine and dioleoyl-sn-glycero-3-phosphocholine (DPPC and DOPC, respectively), were from Avanti Polar Lipids. stBLMs were prepared on goldcoated Si wafers by precipitation of DOPC onto a preformed self-assembled monolayer (SAM) as described [25]. For further details, see Additional Methods.

\section{Electrochemical Impedance Spectroscopy (EIS)}

EI spectra of stBLMs on Si/gold in Teflon (PTFE) sample cells of local design were obtained between $1 \mathrm{~Hz}$ and $65 \mathrm{kHz}$ with ten logarithmically distributed measurements per decade using a Solartron (Farnborough) potentiostat and frequency analyzer. The gold-coated $\mathrm{Si}$ wafer at the bottom of a buffer-filled compartment served as the electrode in connection with a saturated $[\mathrm{Ag}|\mathrm{AgCl}| \mathrm{NaCl}]$ reference and a Pt auxiliary electrode immersed into the buffer. Details are given in Additional Methods.

Fitting of the EI spectra was performed using the electrical equivalent circuit model (ECM) represented in Additional Figure 1B. CPE, or constant-phase element, refers to an electrical element with an impedance, $Z_{\mathrm{CPE}}$ $=1 / \mathrm{T}(\mathrm{i} \omega)^{\alpha}$, where $\mathrm{T}$ is a coefficient measured in Farad per unit area $\times \mathrm{s}^{\alpha-1}$, and the exponent $\alpha$ varies between 0 and 1[25]. The ECM in Additional Figure 1B shows two CPEs, one associated with the capacitive nature of the bilayer $\left(\mathrm{CPE}_{\mathrm{stBLM}}\right)$ and one associated with the capacitive properties of defects in the bilayer $\left(\mathrm{CPE}_{\mathrm{defect}}\right)$. Such defects also give rise to a residual conductance, $\mathrm{Y}$ $=1 / R_{\text {defect }}$. In addition, $R_{\text {solvent }}$ and $C_{\text {stray }}$ describe the resistivity of the buffer and stray capacitance of the sample configuration. Two ECM parameters, $\mathrm{CPE}_{\text {stBLM }}$ and $R_{\text {defect }}$, obtained from the model were used to quantify the quality of as-prepared bilayers and changes in bilayer properties upon incubation with PF-127-dispersed SWCNTs or, as a control, equivalent concentrations of PF-127 alone. If the CPE exponent $\alpha$ equals 1 , the CPE simply reduces to the capacitance, $C$. Since this is the case here (see Table 3), the two ECM parameters represent the bilayer capacitance and the inverse of the residual conductance due to defects.

\section{Langmuir Monolayers (LMs)}

A custom-built Teflon trough (Nima Technology, U.K.) with a surface area of $250 \mathrm{~cm}^{2}$ and a depth of $0.5 \mathrm{~cm}$ on an active anti-vibration table was filled with filtered $\mathrm{H}_{2} \mathrm{O}$ (Milli-Q, Millipore). The surface pressure, $\Pi$, due to a deposited LM was monitored using a Wilhelmy plate, cut from ashfree filter paper and connected to an electronic microbalance. LMs were formed by spreading either DPPC or DOPC dissolved in chloroform using a microsyringe (Hamilton) and allowing the solvent to evaporate for at least $15 \mathrm{~min}$. The resulting LMs were compressed by two symmetrically moving barriers to a desired surface pressure, $\Pi_{0}$. Subsequently, dispersed SWCNT in aqueous solution were injected into the subphase underneath a LM and the ensuing surface pressure change $\Delta \Pi(\mathrm{t})$ was recorded at constant surface area over time, $t$, until it reached at stable plateau. Such experiments, performed at a series of increasing values of $\Pi_{0}$, were used to determine the maximum insertion pressure (MIP), i.e., the minimum value of $\Pi_{0}$ that just suppresses any insertion of the adsorbent into the LM.

\section{Additional material}

Additional File 1: Additional Methods: SWCNT preparation, Sparsely
tethered bilayer lipid membranes (stBLM) preparation,
Electrochemical impedance spectroscopy (EIS). Additional Table 1:
Model-fits of data using the equivalent circuit model (ECM) shown in
Additional Figure 1B for DOPC stBLMs. Additional Figure 1: Schematic of
the stBLM configuration and model used for fitting. Additional Figure 2:
Comparison of vis-NIR spectra suggests that proteins do not displace PF-
127.




\section{Abbreviations}

CPE: constant-phase element; DMEM: Dulbecco's Modified Eagle Medium; DOPC: 1,2-dioleoyl-sn-glycero-3-phosphocholine; DPPC: 1,2-dipalmitoyl-snglycero-3-phosphocholine; ECM: equivalent circuit model; EIS: electrical impedance spectroscopy; FBS: fetal bovine serum; FLIM: fluorescence lifetime imaging microscopy; GPMV: giant plasma membrane vesicle; LM: Langmuir monolayer; PBS: phosphate buffer saline; stBLM: sparsely tethered bilayer lipid membrane; SWCNT: single wall carbon nanotube.

\section{Acknowledgements}

We thank Matteo Broccio, Rima Buvytyte (Vilnius University) and Haw-Zan Goh for help with the EIS studies and David Vanderah at the NIST-CSTL/IBBR for a sample of the tether lipid HC18. This work was supported by the NSF (CBET-0708418 \& DMR-0619424 to KND and MFI), the Sloan Foundation (MFI), the NIH (1P01 AG032131 to ML), the Bertucci Graduate Fellowship $(\mathrm{BDH})$, and the National Defense Science and Engineering Graduate Fellowship (BDH).

\section{Author details}

'Department of Chemical Engineering, Carnegie Mellon University, Pittsburgh, PA, USA. ${ }^{2}$ Department of Biomedical Engineering, Carnegie Mellon University, Pittsburgh, PA, USA. ${ }^{3}$ Department of Physics, Carnegie Mellon University, Pittsburgh, PA, USA. ${ }^{4}$ Center for Neutron Research, The National Institute for Standards and Technology, Gaithersburg, MD, USA. ${ }^{5}$ Department of Materials Science \& Engineering, Carnegie Mellon University, Pittsburgh, PA, USA.

\section{Authors' contributions}

PNY performed membrane and GPMV experiments and prepared manuscript. BDH performed FLIM and Raman experiments. PAS performed endocytosis experiments and transfected cells for FLIM experiments. ML helped design and analyze membrane experiments. MFI provided SWCNTS and helped design and analyze FLIM and Raman experiments. KND provided cells, reagents and rDNA and helped design and analyze cellular experiments. All authors have read and approved the final manuscript.

\section{Competing interests}

The authors declare that they have no competing interests.

Received: 13 May 2011 Accepted: 30 September 2011

Published: 30 September 2011

\section{References}

1. Singh R, Pantarotto D, McCarthy D, Chaloin O, Hoebeke J, Partidos CD, Briand JP, Prato M, Bianco A, Kostarelos K: Binding and condensation of plasmid DNA onto functionalized carbon nanotubes: toward the construction of nanotube-based gene delivery vectors. J Am Chem Soc 2005, 127:4388-4396.

2. Yang R, Yang X, Zhang Z, Zhang Y, Wang S, Cai Z, Jia Y, Ma Y, Zheng C, Lu Y, et al: Single-walled carbon nanotubes-mediated in vivo and in vitro delivery of siRNA into antigen-presenting cells. Gene Ther 2006.

3. Zhang X, Meng L, Lu Q, Fei Z, Dyson PJ: Targeted delivery and controlled release of doxorubicin to cancer cells using modified single wall carbon nanotubes. Biomaterials 2009, 30:6041-6047.

4. Janib SM, Moses AS, Mackay JA: Imaging and drug delivery using theranostic nanoparticles. Adv Drug Deliv Rev 2010, 62:1052-1063.

5. Cherukuri P, Bachilo SM, Litovsky SH, Weisman RB: Near-infrared fluorescence microscopy of single-walled carbon nanotubes in phagocytic cells. J Am Chem Soc 2004, 126:15638-15639.

6. Zhang Y, Hong H, Cai W: Imaging with Raman spectroscopy. Curr Pharm Biotechnol 2010, 11:654-661.

7. Kolosnjaj J, Szwarc H, Moussa F: Toxicity studies of carbon nanotubes. Adv Exp Med Biol 2007, 620:181-204.

8. Kaiser JP, Wick P, Manser P, Spohn P, Bruinink A: Single walled carbon nanotubes (SWCNT) affect cell physiology and cell architecture. J Mater Sci Mater Med 2008, 19:1523-1527.

9. Holt BD, Short PA, Rape AD, Wang YL, Islam MF, Dahl KN: Carbon nanotubes reorganize actin structures in cells and ex vivo. ACS Nano 2010, 4:4872-4878.
10. Albini A, Mussi V, Parodi A, Ventura A, Principi E, Tegami S, Rocchia M, Francheschi E, Sogno I, Cammarota R, et al: Interactions of single-wall carbon nanotubes with endothelial cells. Nanomed 2010, 6:277-288.

11. Jin H, Heller DA, Sharma R, Strano MS: Size-dependent cellular uptake and expulsion of single-walled carbon nanotubes: single particle tracking and a generic uptake model for nanoparticles. ACS Nano 2009, 3:149-158.

12. Jin H, Heller DA, Strano MS: Single-particle tracking of endocytosis and exocytosis of single-walled carbon nanotubes in NIH-3T3 cells. Nano Lett 2008, 8:1577-1585.

13. Heller DA, Baik S, Eurell TE, Strano MS: Single-Walled Carbon Nanotube Spectroscopy in Live Cells: Towards Long-Term Labels and Optical Sensors. Adv Mater 2005, 17:2793-2799.

14. Kam NW, Dai H: Carbon nanotubes as intracellular protein transporters: generality and biological functionality. J Am Chem Soc 2005, 127:6021-6026.

15. Gao H, Shi W, Freund LB: Mechanics of receptor-mediated endocytosis. Proc Natl Acad Sci USA 2005, 102:9469-9474.

16. Li X, Xing D: A simple method to evaluate the optimal size of nanoparticles for endocytosis based on kinetic diffusion of receptors. Appl Phys Lett 2010, 97.

17. Pogodin S, Baulin VA: Can a carbon nanotube pierce through a phospholipid bilayer? ACS Nano 2010, 4:5293-5300.

18. Islam MF, Milkie DE, Torrens ON, Yodh AG, Kikkawa JM: Magnetic heterogeneity and alignment of single wall carbon nanotubes. Phys Rev B 2005, 71:-

19. Islam MF, Rojas E, Bergey DM, Johnson AT, Yodh AG: High weight fraction surfactant solubilization of single-wall carbon nanotubes in water. Nano Lett 2003, 3:269-273.

20. Calvez P, Bussieres $S$, Eric D, Salesse C: Parameters modulating the maximum insertion pressure of proteins and peptides in lipid monolayers. Biochimie 2009, 91:718-733.

21. Desmeules P, Penney SE, Desbat B, Salesse C: Determination of the contribution of the myristoyl group and hydrophobic amino acids of recoverin on its dynamics of binding to lipid monolayers. Biophys J 2007, 93:2069-2082.

22. Shenoy S, Moldovan R, Fitzpatrick J, Vanderah DJ, Deserno M, Lösche M: Inplane homogeneity and lipid dynamics in tethered bilayer lipid membranes (tBLMs). Soft Matter 2010, 6:1263-1274.

23. Dresselhaus MS, Dresselhaus G, Saito R, Jorio A: Raman spectroscopy of carbon nanotubes. Phys Rep 2005, 409:47-99.

24. Choi JH, Nguyen FT, Barone PW, Heller DA, Moll AE, Patel D, Boppart SA, Strano MS: Multimodal biomedical imaging with asymmetric singlewalled carbon nanotube/iron oxide nanoparticle complexes. Nano Lett 2007, 7:861-867.

25. McGillivray DJ, Valincius G, Vanderah DJ, Febo-Ayala W, Woodward JT, Heinrich F, Kasianowicz JJ, Lösche M: Molecular-scale structural and functional characterization of sparsely tethered bilayer lipid membranes. Biointerphases 2007, 2:21-33.

26. Valincius G, McGillivray DJ, Febo-Ayala W, Vanderah DJ, Kasianowicz JJ, Lösche M: Enzyme activity to augment the characterization of tethered bilayer membranes. J Phys Chem B 2006, 110:10213-10216.

27. McGillivray DJ, Valincius G, Heinrich F, Robertson JW, Vanderah DJ, FeboAyala W, Ignatjev I, Lösche M, Kasianowicz JJ: Structure of functional Staphylococcus aureus alpha-hemolysin channels in tethered bilayer lipid membranes. Biophys J 2009, 96:1547-1553.

28. Valincius G, Heinrich F, Budvytyte R, Vanderah DJ, McGillivray DJ, Sokolov Y, Hall JE, Lösche M: Soluble amyloid beta-oligomers affect dielectric membrane properties by bilayer insertion and domain formation: implications for cell toxicity. Biophys J 2008, 95:4845-4861.

29. Barsoukov E, Macdonald JR: In Impedance spectroscopy: theory, experiment, and applications.. 2 edition. Edited by: Hoboken NJ. Wiley-Interscience; 2005:

30. Brockman H: Lipid monolayers: why use half a membrane to characterize protein-membrane interactions? Curr Opin Struct Biol 1999, 9:438-443.

31. Marsh D: Comment on interpretation of mechanochemical properties of lipid bilayer vesicles from the equation of state or pressure-area measurement of the monolayer at the air-water or oil-water interface. Langmuir 2006, 22:2916-2919, discussion 2920-2912.

32. Möhwald H: Phospholipid and phospholipid-protein monolayers at the air/water interface. Annu Rev Phys Chem 1990, 41:441-476. 
33. Blume A: A comparative study of the phase transitions of phospholipid bilayers and monolayers. Biochim Biophys Acta 1979, 557:32-44.

34. Mansour HM, Zografi G: Relationships between equilibrium spreading pressure and phase equilibria of phospholipid bilayers and monolayers at the air-water interface. Langmuir 2007, 23:3809-3819.

35. Wu G, Khant HA, Chiu W, Lee K-YC: Effects of bilayer phases on phospholipid-poloxamer interactions. Soft Matter 2009, 5:1496-1503.

36. Berezin MY, Achilefu S: Fluorescence Lifetime Measurements and Biological Imaging. Chem Rev 2010, 110:2641-2684.

37. Ito T, Oshita S, Nakabayashi T, Sun F, Kinjo M, Ohta N: Fluorescence lifetime images of green fluorescent protein in HeLa cells during TNFalpha induced apoptosis. Photochem Photobiol Sci 2009, 8:763-767.

38. Bianco A, Hoebeke J, Godefroy S, Chaloin O, Pantarotto D, Briand JP, Muller S, Prato M, Partidos CD: Cationic carbon nanotubes bind to CpG oligodeoxynucleotides and enhance their immunostimulatory properties. J Am Chem Soc 2005, 127:58-59.

39. Bianco A, Hoebeke J, Kostarelos K, Prato M, Partidos CD: Carbon nanotubes: on the road to deliver. Curr Drug Deliv 2005, 2:253-259.

40. Heller DA, Jeng ES, Yeung TK, Martinez BM, Moll AE, Gastala JB, Strano MS: Optical detection of DNA conformational polymorphism on singlewalled carbon nanotubes. Science 2006, 311:508-511.

41. Klumpp C, Kostarelos K, Prato M, Bianco A: Functionalized carbon nanotubes as emerging nanovectors for the delivery of therapeutics. Biochim Biophys Acta 2006, 1758:404-412.

42. Kostarelos K, Lacerda L, Pastorin G, Wu W, Wieckowski S, Luangsivilay J, Godefroy S, Pantarotto D, Briand JP, Muller S, et al: Cellular uptake of functionalized carbon nanotubes is independent of functional group and cell type. Nat Nanotechnol 2007, 2:108-113.

43. Shi Kam NW, Jessop TC, Wender PA, Dai H: Nanotube molecular transporters: internalization of carbon nanotube-protein conjugates into Mammalian cells. J Am Chem Soc 2004, 126:6850-6851.

44. Holt BD, Dahl KN, Islam MF: Quantification of uptake and localization of bovine serum albumin stabilized single wall carbon nanotubes into different human cell types. Small 2011, 7:2348-2335.

45. Zhang S, Li J, Lykotrafitis G, Bao G, Suresh S: Size-Dependent Endocytosis of Nanoparticles. Adv Mater 2009, 21:419-424.

46. Chithrani BD, Chan WC: Elucidating the mechanism of cellular uptake and removal of protein-coated gold nanoparticles of different sizes and shapes. Nano Lett 2007, 7:1542-1550.

47. Dai J, Ting-Beall HP, Sheetz MP: The secretion-coupled endocytosis correlates with membrane tension changes in RBL $2 \mathrm{H} 3$ cells. J Gen Physiol 1997, 110:1-10.

48. Sens $P$, Johannes $L$, Bassereau P: Biophysical approaches to proteininduced membrane deformations in trafficking. Curr Opin Cell Biol 2008, 20:476-482.

49. Cherukuri P, Gannon CJ, Leeuw TK, Schmidt HK, Smalley RE, Curley SA, Weisman RB: Mammalian pharmacokinetics of carbon nanotubes using intrinsic near-infrared fluorescence. Proc Natl Acad Sci USA 2006, 103:18882-18886.

50. Baumgart T, Hammond AT, Sengupta P, Hess ST, Holowka DA, Baird BA, Webb WW: Large-scale fluid/fluid phase separation of proteins and lipids in giant plasma membrane vesicles. Proc Natl Acad Sci USA 2007, 104:3165-3170.

51. Holowka D, Baird B: Structural studies on the membrane-bound immunoglobulin E-receptor complex. 1. Characterization of large plasma membrane vesicles from rat basophilic leukemia cells and insertion of amphipathic fluorescent probes. Biochem 1983, 22:3466-3474.

52. Duncan RR, Bergmann A, Cousin MA, Apps DK, Shipston MJ: Multidimensional time-correlated single photon counting (TCSPC) fluorescence lifetime imaging microscopy (FLIM) to detect FRET in cells. J Microsc 2004, 215:1-12.

53. Kollner M, Wolfrum J: How Many Photons Are Necessary for Fluorescence-Lifetime Measurements. Chem Phys Lett 1992, 200:199-204.

54. Becker W: The bh TCSPC handbook - Third Edition 2008.

55. Vakarelski IU, Brown SC, Higashitani K, Moudgil BM: Penetration of living cell membranes with fortified carbon nanotube tips. Langmuir 2007, 23:10893-10896

56. Heinrich F, Ng T, Vanderah DJ, Shekhar P, Mihailescu M, Nanda H, Lösche M: A New Lipid Anchor for Sparsely Tethered Bilayer Lipid Membranes. Langmuir 2009, 25:4219-4229.
57. Vanderah DJ, Meuse CW, Silin V, Plant AL: Synthesis and characterization of self-assembled monolayers of alkylated 1-thiahexa(ethylene oxide) compounds on gold. Langmuir 1998, 14:6916-6923.

doi:10.1186/1477-3155-9-45

Cite this article as: Yaron et al: Single wall carbon nanotubes enter cells by endocytosis and not membrane penetration. Journal of

Nanobiotechnology 2011 9:45.

\section{Submit your next manuscript to BioMed Central and take full advantage of:}

- Convenient online submission

- Thorough peer review

- No space constraints or color figure charges

- Immediate publication on acceptance

- Inclusion in PubMed, CAS, Scopus and Google Scholar

- Research which is freely available for redistribution

Submit your manuscript at www.biomedcentral.com/submit
Ciomed Central 